\section{Progressive pulmonary stenosis due to huge mediastinal thymoma}

A 61-year-old male was presented with shortness of breath, and there was a mediastinal enlargement in the chest radiography. Thorax computed tomography (CT) showed an anterior mediastinal mass with $18 \times 10 \times 12 \mathrm{~cm}$ size that pushed the heart and main vascular structures posteriorly (Fig. 1). Positron emission tomography showed an increased fluorodeoxyglucose uptake. Therefore, a biopsy was performed, which proved that thymoma Type B2 is present. Although external mild right pulmonary artery (RPA) compression was observed on CT, transthoracic echocardiography (TTE) did not show a significant gradient. After 9 months, the patient presented with increased dyspnea and chest pain. The admission CT showed increased diameters of thymoma $(19 \times 12 \times 15 \mathrm{~cm})$, with severe compression on the left atrium (LA) and RPA (Fig. 2). TTE showed an anteriorly located mass image in the parasternal view that pushed the heart posteriorly (Fig. 3a), LA compression in the apical views (Fig. $3 \mathrm{~b}$ and $3 \mathrm{c}$ ), and moderate pulmonary stenosis with $48 \mathrm{~mm} \mathrm{Hg}$ maximum gradient in the subcostal view, as parasternal short axis view was poor (Fig. 3d). Surgical excision was planned after chemotherapy by the multidisciplinary team.

Acquired pulmonary stenosis in adults is rare and mediastinal tumor external compression is one of the common causes (1).
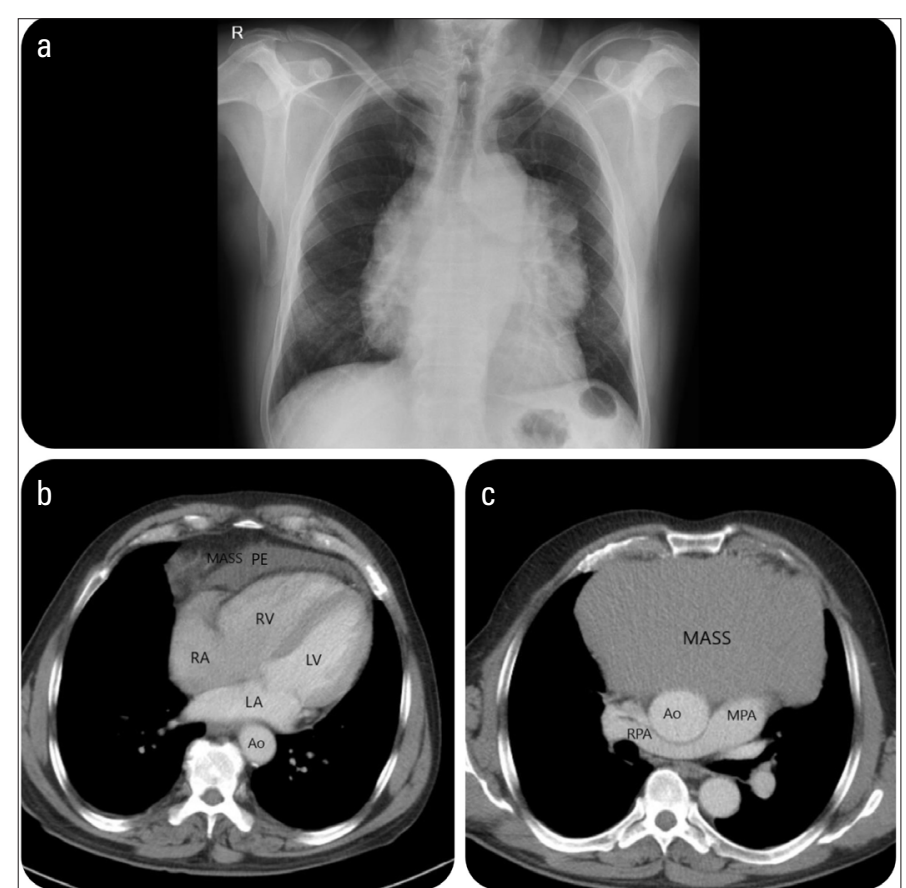

Figure 1. (a) Posteroanterior chest radiography shows mediastinal enlargement. (b) Thorax computed tomography (CT) shows a mass in the axial plane, PE adjacent to RV, and mild compression on the LA. (c) Large mass located in the anterior mediastinum is observed; vascular structures are displaced posteriorly, and there is mild compression on the RPA RV - right ventricle; LV - left ventricle; RA - right atrium; LA - left atrium; Ao - aorta; MPA - main pulmonary artery; RPA - right pulmonary artery; PE - pericardial effusion
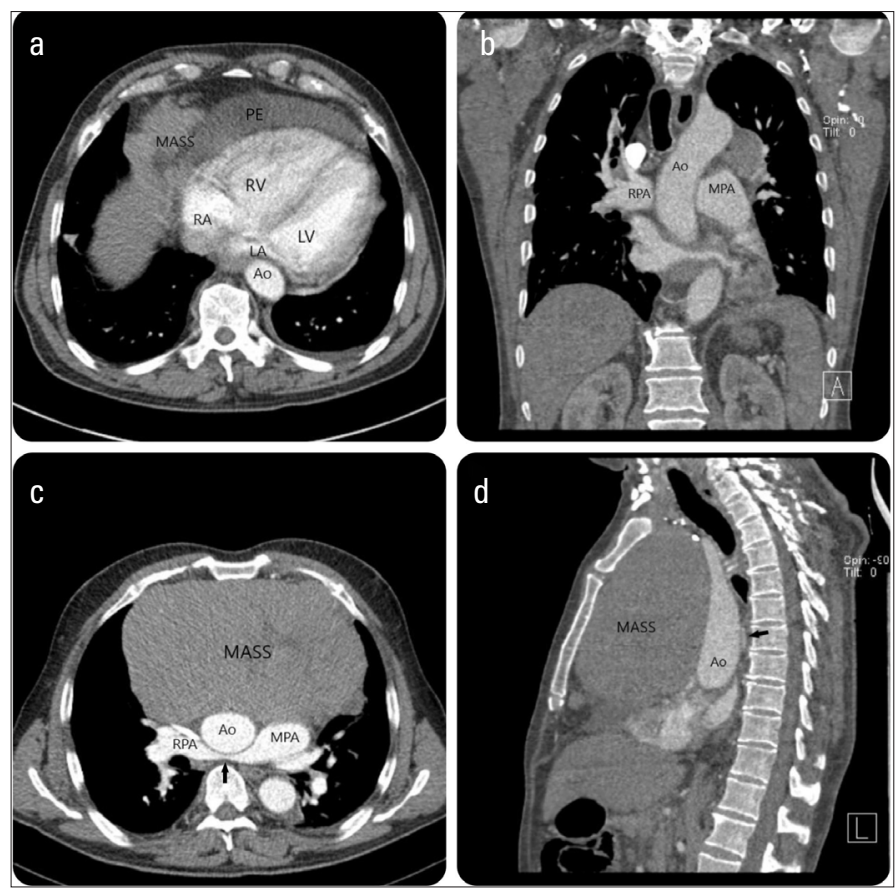

Figure 2. Contrast-enhanced thorax CT examination. (a) Pericardial effusion adjacent to the $R V$, severe compression to the $L A$, and a mass are seen in the axial plane. (b) In the coronal plane, the area of the RPA exposed to compression behind the aorta is seen. (c) Severe compression on the RPA (black arrow) is seen with a giant mass in the axial plane. (d) In the sagittal plane, advanced compression is seen on RPA behind the aorta (black arrow) RV - right ventricle; LV - left ventricle; RA - right atrium; LA - left atrium; Ao - aorta; MPA - main pulmonary artery; RPA - right pulmonary artery; PE - pericardial effusion
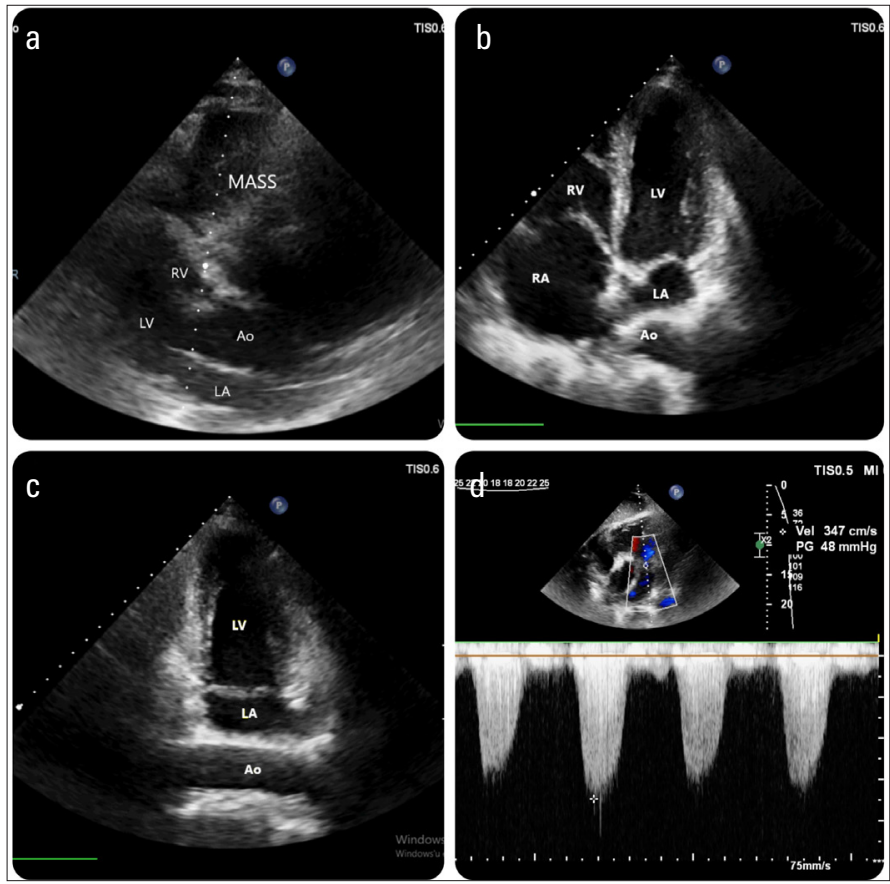

Figure 3. Transthoracic echocardiography. (a) The parasternal long-axis view shows a giant mass and posterior displacement of the heart. (b) and (c) Apical 4 and 2 chamber images show compression to the LA. (d) In the subcostal image, $48 \mathrm{~mm} \mathrm{Hg}$ maximum gradient is observed in the pulmonary artery with continuous wave (CW) doppler

RV - right ventricle; LV - left ventricle; RA - right atrium; LA - left atrium; Ao - aorta 
Thymomas are the most common tumors of the anterior mediastinum (2). They can reach large diameters and cause cough, shortness of breath, and chest pain. Total surgical resection is the basis of treatment, and applied in combination with radiotherapy and chemotherapy in advanced invasive thymomas (2).

Informed consent: Written informed consent was obtained from the patient.

\section{References}

1. Robinson T, Lynch J, Grech E. Non-Hodgkin's lymphoma causing extrinsic pulmonary artery compression. Eur J Echocardiogr 2008; 9: 577-8. [Crossref]

2. Bushan $\mathrm{K}$, Sharma $\mathrm{S}$, Verma H. A review of thymic tumors. Indian J Surg Oncol 2013; 4: 112-6. [Crossref]
Murat Çap* (D), Emrah Erdoğan1 (D, Abdurrahman Akyüz* (D), Neşe Kanbal Çap2 (i), Erkan Erdur** (i)

Departments of *Cardiology, and ${ }^{* *}$ Oncology, University of Health Sciences, Gazi Yaşargil Training and Research Hospital; Diyarbakır-Turkey

'Department of Cardiology, Faculty of Medicine, Van Yüzüncü Yıl University; Van-Turkey

2Department of Internal Medicine, Faculty of Medicine, Dicle University; Diyarbakır-Turkey

Address for Correspondence: Dr. Murat Çap,

Sağlık Bilimleri Üniversitesi, Gazi Yaşargil Eğitim ve Araştırma Hastanesi,

Kardiyoloji Anabilim Dalı, Diyarbakır-Türkiye

Phone: +90 5320586384

E-mail: murat00418@hotmail.com

(C) Copyright 2021 by Turkish Society of Cardiology -

Available online at

www.anatoljcardiol.com

DOI:10.5152/AnatolJCardiol.2021.11069 